\title{
ARGILOTERAPIA: UMA REVISÃO DE LITERATURA SOBRE OS CONSTITUINTES E UTILIZAÇÕES DOS DIFERENTES TIPOS DE ARGILA
}

\author{
Amanda Truppel ${ }^{1}$ \\ Hellen Camila Marafon ${ }^{22}$ \\ Caroline Valente ${ }^{33}$
}

\begin{abstract}
Resumo: A argila é um dos compostos mais antigos conhecido pelo homem, mesmo sendo uma matéria prima abundante e muito utilizada na cerâmica, seu uso como técnica terapêutica é pouco difundida. Sabe-se que é recurso poderoso devido à grande quantidade de minerais. Sua composição físico-química indica a sua utilização, que vai desde absorver impurezas, revigorar tecidos e ativar a circulação, além da ação tensora, estimulante, suavizante e catalisadora. Mediante essas particularidades, o presente trabalho teve como objetivo revisar na literatura a eficácia da geoterapia nos tratamentos terapêuticos e estéticos. Trata-se de uma revisão bibliográfica desenvolvida a partir da literatura disponível entre os anos de 1990 até 2016, pesquisada nos bancos de dados do Google acadêmico, SciELO e livros relacionados ao assunto. Sendo assim, foi elaborada uma tabela com informações das doenças e tratamentos geoterápicos a serem utilizados. Conclui-se neste trabalho que as argilas trazem satisfatórios resultados quando utilizadas em tratamentos estéticos e tratamentos medicinais. Seu resultado dependerá da cor da argila, sendo as cores verde, rosa, branca e vermelha as mais utilizadas.
\end{abstract}

Palavras-chave: Argiloterapia. Geoterapia. Argila. Argila Medicinal.

\section{CLAYTHERAPY: A LITERATURE REVIEW ON THE CONSTITUENTS AND USES OF DIFFERENT TYPES OF CLAY}

\begin{abstract}
Clay is one of the oldest compounds known to man, even though it is an abundant raw material and widely used in ceramics, its use as a therapeutic technique is not widespread. It is known that it is a powerful resource due to the large amount of minerals. Its physical-chemical composition indicates its use, which ranges from absorbing impurities, invigorating tissues and activating circulation, in addition to the tensor, stimulating, smoothing and catalyzing action. Given these particularities, the present study aimed to review in the literature the effectiveness of geotherapy in therapeutic and aesthetic treatments. It is a bibliographical review developed from the available literature between the years of 1990 and 2016 searched in the databases of Google academic, SciELO and books related to the subject; thus, a table with information of diseases and geotherapeutic treatments was elaborated. It is concluded in this work that clays bring satisfactory results when used in aesthetic and medicinal treatments. Its result will depend on the color of the clay, such as green, pink, white and red the most used.
\end{abstract}

Keywords: Claytherapy, Geotherapy. Clay. Medicinal Clay.

\section{Introdução}

Argiloterapia é uma palavra que vem do grego: geo significa terra e terapia, está relacionada a tratamento. É uma técnica natural e, provavelmente, a mais antiga utilizada pelo homem como método alternativo para uso terapêutico e estético.

São utilizados vários tipos de argila, sendo que cada uma tem suas indicações conforme suas características físico-químicas. Além disso, podem ser utilizadas em diferentes temperaturas, técnicas de aplicações e tempo de permanência.

\footnotetext{
${ }^{1}$ Biomédica. Departamento de Farmácia. Centro de Ciências da Saúde. Universidade Regional de Blumenau-FURB. Blumenau-SC. amanda-truppel@ hotmail.com

${ }^{2}$ Acadêmica do Curso de Graduação em Medicina. Universidade Estadual do Oeste do Paraná-Unioeste. Campus Francisco Beltrão. Francisco Beltrão-PR. hellencmarafon@gmail.com

${ }^{3}$ Farmacêutica, Acupunturista e Professora. Departamento de Ciências Naturais. Centro de Ciências Exatas e Naturais. Universidade Regional de Blumenau-FURB. Blumenau-SC. carolvalente11@gmail.com
} 
A argila possui a capacidade de absorver impurezas, revigorar os tecidos e ativar a circulação e, por isso, apresenta potencial para aplicações cosméticas e terapêuticas. Além disso, possui ação tensora, estimulante, amaciante, suavizante e tem a capacidade de absorver a oleosidade da pele. Tal fato é possível pela quantidade de minerais presentes em sua composição, como: ferro, magnésio, potássio, silício, alumínio e outros. De acordo com estudos, a argila repõe minerais, estimula a atividade de certas enzimas e possui poder de reter em suas moléculas substâncias que são nocivas ao nosso organismo. Há relatos que a aplicação da argila responde positivamente no alívio de dores, em processos anti-inflamatórios e auxilia na tonificação da pele.

Mesmo tendo funções terapêuticas reconhecidas há milênios, apenas há alguns anos começaram estudos acerca do tratamento milenar conhecido como argiloterapia ou geoterapia. Desta maneira, há um déficit literário muito amplo sobre este tema, são encontrados em livros apenas definições técnicas da composição química da argila, bem como suas funções na cerâmica, área voltada para a construção civil.

A pesquisa proposta poderá propiciar à área da saúde e da estética um novo foco de pesquisa para a utilização da argila em seus tratamentos. Sendo assim, foi desenvolvido um levantamento sobre características, tipos, composições e funções da argila, visando à elaboração de uma tabela indicando a enfermidade e a região do corpo a qual deve ser aplicada.

\section{Revisão de Literatura}

\section{História da argila}

Trata-se da substância mais antiga usada pelo homem. A argila possui seu uso terapêutico reportado há mais ou menos 3.000 anos (BOURGEIOIS, 2006). A técnica utilizada para aplicação da argila foi baseada na observação de animais feridos que procuravam certos tipos de 'lamas" para tratamento de suas feridas, este foi o mecanismo responsável pela descoberta de diversas argilas medicinais (PERETTO, 2008).

Antigas civilizações do Oriente, como os egípcios, já utilizavam o material argiloso com princípio de cura, para tratar inflamações e doenças internas. Devido ao poder de purificação e antissepsia da argila, embalsamadores usavam deste material para mumificação de corpos (BOURGEIOIS, 2006). Segundo Peretto (2008), o grande filósofo Aristóteles retratou a argila como um método que preserva e trata a saúde, já Galileno e Discorde, anatomistas gregos, descrevem em seus escritos a utilização da argila no uso de tratamento à saúde, confirmando a sua eficácia. 
O grandioso médico grego Hipócrates, renomado pai da medicina, usava e ensinava aos seus discípulos o uso da argila de forma medicinal. O unificador da Índia, Mahatma Gandhi, instruía a cura pela argila e, graças a ele, naturólogos alemães, como Luis Kuhne e Adolf Just, deixam relatos importantes sobre tratamentos utilizando a argila no século XX (PERETTO, 2008).

Já na América, grupos de índios cultivavam a tradição de que seus doentes terminais deveriam ser enterrados na posição vertical, deixando somente a cabeça para fora para que, assim, ficassem em contato com a terra o maior tempo possível. Essa técnica também foi utilizada na guerra do Vietnã, quando coreanos e vietnamitas tomavam banho de argila para cuidar de suas queimaduras (DORNELLAS e MARTINS, 2009). Para desintoxicar, transformar, equilibrar e melhorar a circulação do Qi (energia), a medicina Oriental também emprega a argila, utilizando-a sozinha ou em conjunto com outros materiais. Já no Brasil, um país rico em quantidade de argila, porém, ainda pequeno no uso com finalidade para tratamentos em saúde, somente algumas clínicas, spas profissionais e balneários atendem com objetivo terapêutico (DORNELlAS e MARTINS, 2009). Alguns países, como Alemanha, Cuba, Rússia, Israel e Itália, já possuem centros terapêuticos para várias doenças, como infecções de pele e dores musculares, com utilização da geoterapia em parte do tratamento (BRASIL, 2007).

\section{Argila}

É um composto de material sedimentar constituído por granulações finas, e quando é umedecido com água, obtém uma plasticidade que se designa então o nome de "argila" (DÍAZ, 2005; DEBACHER e MELLO, 2004). São subdivididas em argilas primárias e secundárias. As primárias são encontradas na forma de pó decorrentes da decomposição do sol, já as argilas secundárias, encontram-se na forma de lama (água mais argila), originadas através do transporte de chuvas e ventos (DORNELLAS e MARTINS, 2009).

Sendo as formulações disponíveis bastante variadas tanto em cores quanto na sua composição, é a presença de seus componentes que determinam o seu mecanismo e o seu modo de uso. Suas características são demostradas através de sua matéria orgânica ou do mineral encontrado em sua composição (FONTES et al, 2001). Segundo Langreo (1999), podendo ser encontradas em diferentes profundidades e alturas, frequentemente são extraídas de jazidas e, então, levadas a indústrias para serem processadas e manipuladas. A argila é escolhida e examinada por meio de culturas microbiológicas para investigar a presença de fungos, leveduras, bactérias ou qualquer outro tipo de contaminação. 
A argila consiste em camadas de alumina, hidroxila e silicatos, por isso, é descrita quimicamente como silicato de alumínio hidratado. Dispõe-se em arranjos lamelares compostos por lâminas tetraédricas e octaédricas, conhecidas como filosilicatos (estruturas em chapas encontradas em minerais argilosas). As estruturas octaédricas constituem-se de alumínio ( $\left.\mathrm{Al}^{3+}\right)$, envolto por hidroxilas $\left(\mathrm{OH}^{-}\right)$nas estruturas tetraédricas, a sílica é envolta por íons de oxigênio. A combinação dessas lâminas constituídas por camadas sobrepostas é que dá estrutura aos minerais de argila (MEDEIROS, 2007).

As argilas possuem inúmeras utilidades conhecidas, como, por exemplo, na cerâmica, mas também podem ser utilizadas em tratamentos de estética e de saúde (SILVA et al, 2015). Conforme os autores Dornellas e Martins (2009), a argila e os elementos minerais presentes na sua composição físico-química atuam nos tratamentos de saúde e estéticos nas seguintes condições:

- Alumínio: age para a tonicidade da pele, tem atuação cicatrizante, podendo inibir até o crescimento de algumas bactérias como a Staphylococcus aureus;

- Ferro: fundamental para a respiração celular e transferência de elétrons. Na pele, a falta deste mineral manifesta-se por uma epiderme fina, seca e sem elasticidade;

- Magnésio: tem o poder de fixar os íons de potássio e do cálcio, com papel importante na formação e manutenção celular;

- Manganês: sua ação é específica na biossíntese do colágeno, tem ação anti-infecciosa, cicatrizante e antialérgica;

- Silício: tem papel importante na reconstituição dos tecidos cutâneos e na defesa do tecido conjuntivo. Tem ação hemostática, purificante, adstringente e remineralizante. Tem efeito hidratante na pele e reduz as inflamações. Também, possui papel na elasticidade da pele, atuando em flacidez cutânea;

- Sódio e potássio: Ajudam a preservar o equilíbrio iônico das células cutâneas.

\section{Tipos de argila}

A argila foi classificada de acordo com as suas cores, as quais estão relacionadas com as características físico-químicas presentes na sua formação. A (Figura 1) representa as diferentes cores que a argila pode possuir (MEDEIROS, 2013).

Figura 1 - Diferentes tipo de argila 


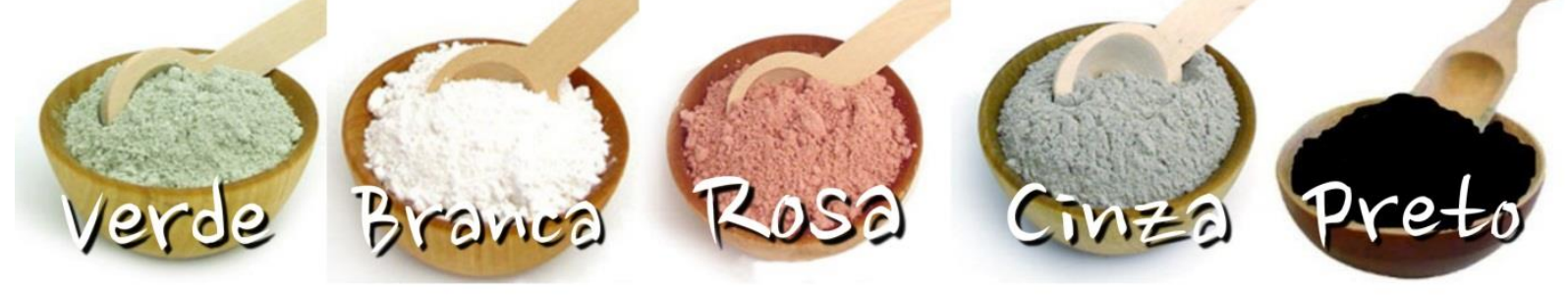

Fonte: Santos, 2015

a) Argila Branca: também conhecida como caulim, essa argila é naturalmente misturada com outros tipos de argila para suavizar os efeitos intensos das outras cores (SOUZA, 2005). Sua composição mineralógica corresponde a uma mistura de caolinita e quartzo. Possui alta quantidade de alumínio, fato que lhe concede propriedade cicatrizante, seu uso na estética promove ação antisséptica e facilita a circulação sanguínea (SOUZA, 2005). Conforme Medeiros (2013), é comprovado que a argila branca tem ótimos feitos em suavizar rugas e linhas de expressão. No caso de manchas provocadas pela exposição solar são utilizadas aplicações de argila nesta cor. Muito utilizada em esfoliações faciais (peeling), principalmente em peles sensíveis. Nutre a pele com efeito depurativo, tensor, suave e revitalizante (MEDEIROS, 2013; PERETTO, 1999). Na argila branca encontram-se os seguintes elementos: alumínio (Al); óxido de magnésio $(\mathrm{MgO})$; óxido de cálcio $(\mathrm{CaO})$; enxofre $(\mathrm{S})$; ferro $(\mathrm{Fe})$; boro $(\mathrm{B})$; potássio $(\mathrm{K})$; cálcio (Ca); silício (Si) e óxido de enxofre ( $\left.\mathrm{SO}_{3}\right)$ (MEDEIROS, 2013; SAMPAIO et al, 2008).

b) Argila Verde ou Acinzentada: conhecida como montmorilonita, rica em zinco e silício, é a argila mais utilizada atualmente. Proporciona a atividade sebo-reguladora. É indicada no uso de vários tratamentos, principalmente em casos crônicos (MEDEIROS, 2013). A presença de oxido de ferro é o que difere a sua cor, que atua em união a outros minerais, tais como o quartzo, ilita e caolinita (RIBEIRO, 2010). Na estética, pode atuar como redutora de celulite e flacidez, e é muito indicada para regulação da oleosidade, principalmente para estética facial (RIBEIRO, 2010). A argila verde melhora a circulação sanguínea, promove a eliminação de toxinas e descongestiona a circulação linfática, favorecendo o efeito de drenagem, isso se deve ao seu aporte nutricional e por ser considerada uma cor neutra e natural, podendo ser utilizada como esfoliante suave (MEDEIROS, 2013). A cor tranquilizante, tonificante e refrescante, auxilia os pacientes com insônia, irritação e dor de cabeça, evitando o acúmulo de energias negativas e estresse mental (CORVO e BONDS, 1997). Dentre os elementos encontrados na argila verde estão o óxido de sódio $\left(\mathrm{Na}_{2} \mathrm{O}\right)$; zinco $(\mathrm{Zn})$; monóxido de potássio $\left(\mathrm{K}_{2} \mathrm{O}\right)$; manganês $(\mathrm{Mn})$; cobre $(\mathrm{Cu})$; alumínio $(\mathrm{Al})$; silício $(\mathrm{Si})$; molibdênio $(\mathrm{Mo})$; óxido de titânio $\left(\mathrm{TiO}_{2}\right)$; lítio $(\mathrm{Li})$; sódio (Na) e potássio (K) (SAMPAIO et al, 2008; MEDEIROS, 2013). 
c) Argila Vermelha: é a argila mais rica em óxido de ferro, resultando em propriedades tensoras. Esta cor é universalmente considerada a cor do fogo, que simboliza força, poder e brilho (RIBEIRO, 2010). Na estética, tem ação reguladora do fluxo sanguíneo, sendo muito indicada para peles sensíveis (MEDEIROS, 2013). O seu uso é contraindicado nos casos de pessoas agitadas, ansiosas, com inflamações ou que estejam sob o efeito de estresse, pois esta cor irá aumentar o fluxo sanguíneo e o calor (MEDEIROS, 2013). Os principais elementos presentes na argila vermelha com suas respectivas estruturas são: óxido de magnésio $(\mathrm{MgO})$; sódio $(\mathrm{Na})$; óxido de ferro $\left(\mathrm{Fe}_{2} \mathrm{O}_{3}\right)$; óxido de cobre $(\mathrm{CuO})$; óxido de potássio $\left(\mathrm{K}_{2} \mathrm{O}\right)$; ferro $(\mathrm{Fe})$; cobre $(\mathrm{Cu})$ e cromo (Cr) (SAMPAIO et al, 2008; MEDEIROS, 2013).

d) Argila Amarela: por conter silício e alumínio, possui o efeito desinfiltrante, adstringente e desintoxicante (MEDEIROS, 2007). Indicada para peles pós-verão, por possuir efeito tônico e revitalizante, tem a propriedade de nutrir, tonificar, e oxigenar a pele. Sua análise química possui concentração de cobre, ferro e magnésio (MEDEIROS, 2013). O amarelo representa a intensidade, o símbolo da juventude e do vigor. A argila amarela elimina todos os resíduos impuros, retirando manchas e auxiliando na digestão de alimentos, evitando a prisão de ventre. Também auxilia na circulação, aliviando dores (VILA Y CAMPANYA, 2000; MEDEIROS, 2013). O seu uso é contra indicado nos casos de diarreia, febre e inflamações agudas, devido aos elementos presentes em sua estrutura: cálcio $(\mathrm{Ca})$; cobre $(\mathrm{Cu})$, manganês (Mn); ferro (Fe); magnésio (Mg); e potássio (K) (SAMPAIO et al, 2008; MEDEIROS 2013).

e) Argila Roxa: ideal para peles cansadas e com linhas de expressão aumentadas, também pode ser utilizada para o aumento da circulação e da hidratação. Reconstrói a vitalidade da pele, reduzindo edemas após limpeza facial (MEDEIROS, 2013). Para ação terapêutica é indicada principalmente em queimaduras de primeiro grau, por possuir efeitos cicatrizante e analgésico (MEDEIROS, 2013).

f) Argila Rosa: uma mistura da argila branca e vermelha, promove elasticidade e tonificação, por isso é argila mais comum na estética. Melhora o sistema imunológico, realça o brilho e a maciez (MEDEIROS, 2013). Sua composição de mineral é a mistura de quartzo, esmectita, ilita e caolinita (RIBEIRO, 2010). A cor rosa representa a cor do apoio e possui uma beleza capaz de curar, além disso, traz consigo a promessa do preenchimento, dando a sensação de conforto, autovalorização e autoconfiança. Ativa, também, a circulação com efeitos emolientes e antioxidantes (MEDEIRO, 2013; BONDS, 1999). Seus componentes presentes são as respectivas estruturas cristalinas: óxido de ferro $\left(\mathrm{Fe}_{2} \mathrm{O}_{3}\right)$; sódio $(\mathrm{Na})$ e óxido de cobre $\left(\mathrm{Cu}_{2} \mathrm{O}\right)$ (SAMPAIO et al, 2008; MEDEIROS, 2013). 
g) Argila Cinza: bastante indicada para terapia capilar, controla a seborreia, auxilia na reconstrução da pele em casos de ferimentos, lesões por assaduras ou atritos (MEDEIROS, 2013).

h) Argila Preta/Negra: por ser obtida das profundidas, é raramente encontrada pura (RIBEIRO, 2010). Promove a melhora da circulação sanguínea, aliviando a dormência das extremidades dos membros (MEDEIROS, 2007). Por sua grande quantidade de enxofre e matéria orgânica e a presença do titânio agrupado a elevados graus de alumínio e silício, é um material excelente para ser utilizado no rejuvenescimento da pele (DORNELLAS e MARTINS, 2009; CARVALHO, 2009). Os principais componentes presentes em sua estrutura são: alumínio (Al); titânio (Ti); magnésio (Mg); zinco ( $\mathrm{Zn}$ ); ferro (Fe) e enxofre (S) (MEDEIROS, 2013; SAMPAIO et al, 2008).

i) Cristais de Quartzo: devem ser utilizados antes da aplicação para todos os procedimentos com uso de argila, pois, possui um efeito energético, tornando a pele mais receptiva para os nutrientes da geoterapia (MEDEIROS, 2013). São utilizados tanto na esfoliação facial quanto na corporal. Aqueles que possuírem grânulos maiores são indicados somente para esfoliação corporal. Já aqueles de grânulos menores, para esfoliação facial ou corporal, em caso de pele sensível (MEDEIROS, 2013).

\section{Argila Terapêutica}

Aplicada no tratamento medicinal, a argila atua como material anti-inflamatório, refrescante, desintoxicante, cicatrizante e calmante, fortalecendo os órgãos internos. Elimina as células mortas ou danificadas e as impurezas, além de agir como bactericida e antiparasitária. A argila não somente absorve os germes perigosos, mas também é capaz de regenerar os tecidos danificados através de seus elementos físico-químicos (CLAUDINO, 2010).

Sua ação vital pode alcançar o sistema nervoso central, aliviando dores e tensões. Quando a argila é utilizada fria, absorve a febre dos tecidos, diminuindo as dores das inflamações e levando ao equilíbrio térmico do corpo. Já quando usada morna ou quente, suaviza os tecidos deixando-os relaxados (PERRETO,2008).

Segundo os autores Dornellas e Martins (2009), são os elementos minerais como ferro, silício e magnésio presentes na argila, que lhe concedem as propriedades terapêticas essenciais relatadas a seguir:

- Absorção: obtém elasticidade quando misturada com água, adquirindo uma pasta eficaz no tratamento de inflamações, edemas e inchaços; 
- Liberação: possui capacidade para liberar elementos ativos que fazem parte de sua constituição, produzindo efeito protetor e absorvedor de toxinas em vários órgãos, principalmente na pele e mucosas;

- Adsorção: constitui um fenômeno no qual a argila deixa passar moléculas, elementos gasosos e partículas microscópicas do meio ambiente com o intuito de deslizar para o interior da pele; este processo é muito útil na fixação de toxinas presentes no organismo para uma posterior eliminação destas.

É a união de determinados elementos minerais presentes na argila que lhe concede as propriedades de cura, provocando no organismo os seguintes efeitos:

- Libera os interstícios celulares;

- Elimina toxinas;

- Promove a microcirculação cutânea;

- Em algumas religiões, permite a troca de energia dos minerais com a parte afetada;

- Promove uma microabrasão (peeling suave);

- Regula a produção sebácea;

- Regula a queratinização;

- Regulariza a temperatura do órgão enfermo, uniformizando a irrigação sanguínea (DORNELLAS e MARTINS, 2009).

São inúmeras as utilidades terapêuticas das argilas, indicadas para o tratamento de várias enfermidades. Deve-se observar, além da indicação terapêutica, a forma, o local da aplicação e a temperatura da argila a ser utilizada (VILA Y CAMPANYA, 2000). A temperatura da argila aplicada irá depender do local do corpo beneficiado pelo tratamento, ou seja, em locais excessivamente frios, pode-se aplicar a argila um pouco aquecida, já em locais quentes, deve-se usá-la em temperatura ambiente (MEIDEIROS, 2013).

Segundo Claudino (2010), a argila pode ser utilizada para vários casos devido a sua diversidade de funções, como adsorção de toxinas inflamatórias, ação bactericida, e antisséptica.

Conforme Peretto (2008), a argila, para fins terapêuticos, deve ser aplicada em camadas mais grossas e, para fins estéticos, usar uma camada mais fina. $\mathrm{O}$ uso de argilas com óleos essenciais dá ótimos resultados estéticos e terapêuticos. Na figura 2, podemos observar uso terapêutico da argila.

Figura 2 - Aplicação da argila: finalidade terapêutica. 


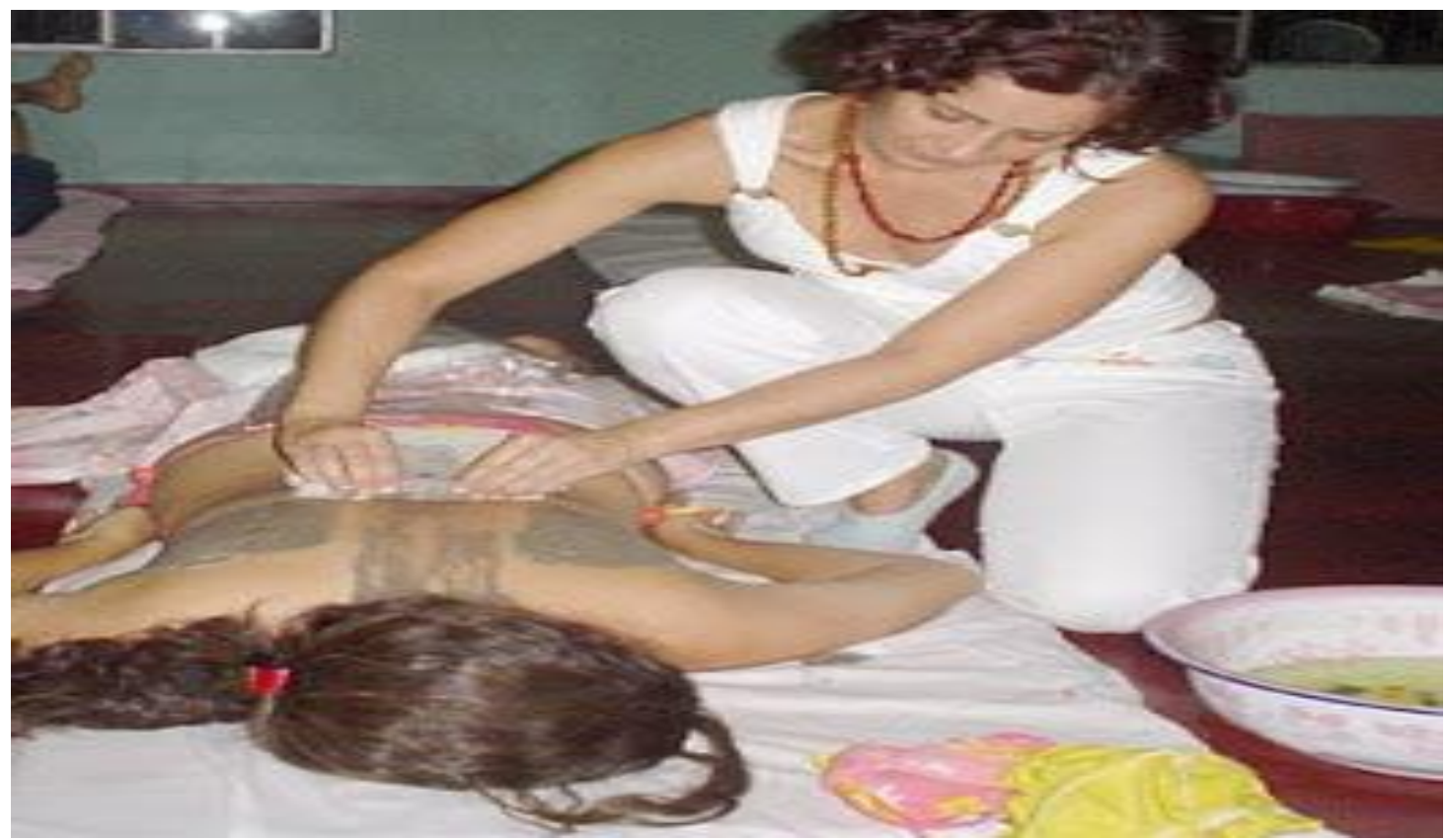

Fonte: Lamaita, 2009.

\section{Argilas na estética}

Dadas as suas virtudes terapêuticas, auxiliando em causas infeciosas, ativando a circulação linfática e a sanguínea e ajudando nas atividades das glândulas sebáceas, a argila passou a ser inserida em inúmeras marcas conceituadas de cosméticos. Deste modo, quando é inserida ao ingrediente cosmético, em uma máscara facial, por exemplo, ela atua simultaneamente como uma máscara ou um esfoliante. Portanto, quanto mais simples o cosmético, melhor (PERETTO, 2008).

As máscaras de argila são utilizadas para nutrir, limpar e revitalizar a pele por meio de um processo de expulsão de toxinas, estimulando a circulação por causa de seu gênero queratolítico. Essas características dependem de qual é o tipo de argila utilizada para o tratamento (SOUZA, 2005).

Em tratamentos estéticos, a argila funciona como tonificante corporal e auxilia na drenagem linfática quando aplicada em compressas em áreas de concentração de gânglios, promovendo a eliminação de toxinas (DORNELLAS e MARTINS, 2009).

Se quisermos um ótimo desinfetante, podemos recorrer à terra. Ela ajuda a combater processos infecciosos, ativando a circulação sanguínea e linfática, o fluxo nervoso e as atividades das glândulas sebáceas (PERETTO, 2008). Na figura 3, observamos o uso da argila no tratamento estético facial.

Figura 3 - Aplicação de argila: finalidade estética 


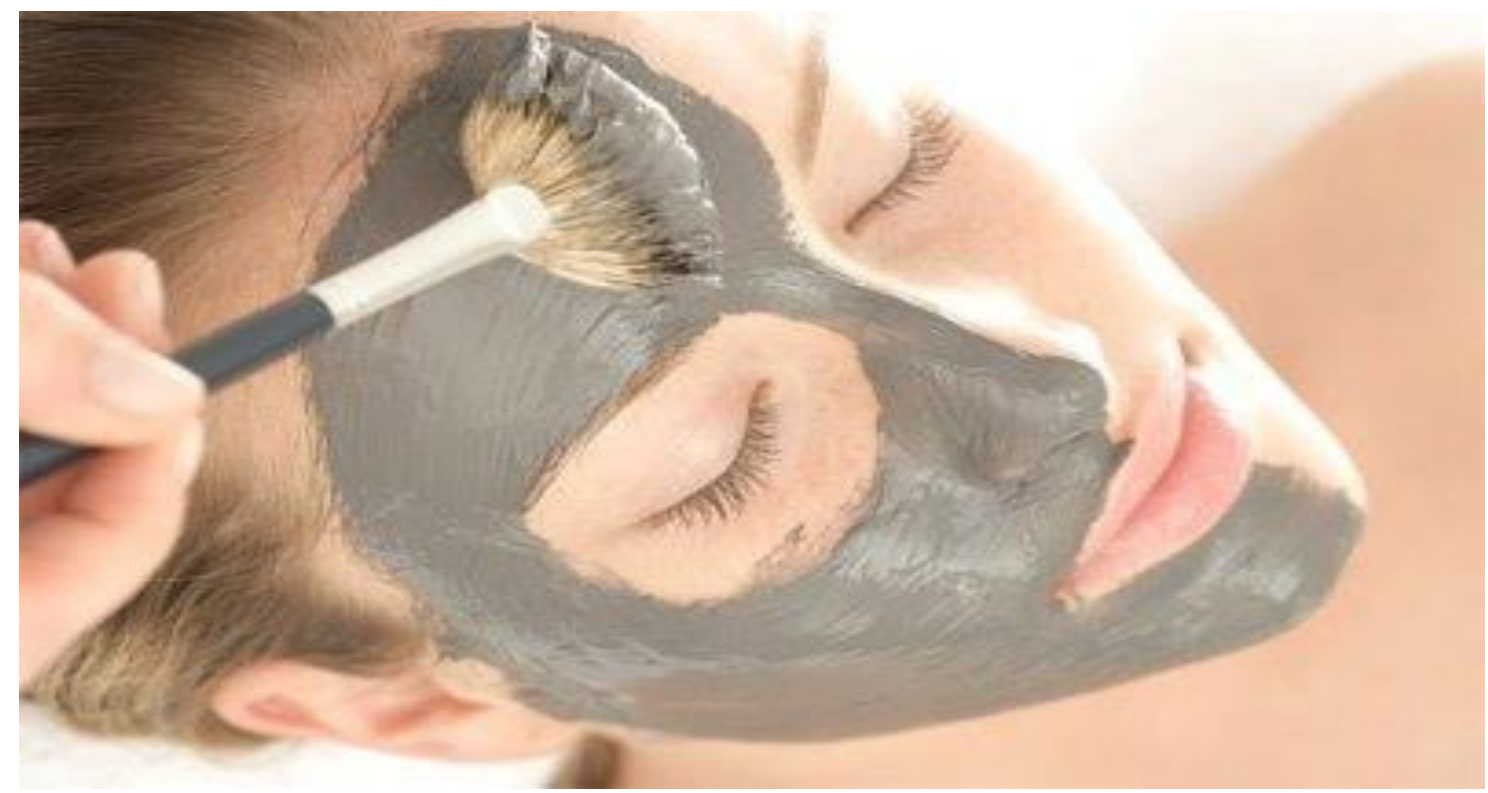

Fonte: Muller, 2009.

\section{Tempo de duração do tratamento}

Pode variar muito, em casos agudos o resultado pode ser imediato, entretanto, em casos crônicos, a cura pode levar até 40 dias e alguns casos exigem até um ano (PERETTO, 2008).

Uma vez iniciado, o tratamento não deve ser interrompido antes de se conseguir o resultado desejado, pois a argila desencadeia processos sucessivos de purificação e revitalização. Se houver interrupções, mesmo que provisória, a sequência dos processos será interrompida e será necessário começar tudo novamente da estaca zero (PERETTO, 2008).

\section{Tempo de duração da aplicação}

O tempo de aplicação também é muito variado, pode ser de uma ou duas horas, ou se estender durante a noite. Este tempo irá depender do local e do problema que deseja ser solucionado (PERETTO, 2008).

Em alguns tratamentos, a argila deve ser retirada antes do tempo previsto, principalmente, em casos nos quais o produto esquenta com o calor do corpo e então o problema não será solucionado (PERETTO, 2008).

\section{Cosméticos de argila}

Os cosméticos feitos com argila servem não somente como embelezamento para quem usa, mas também para prevenir e melhorar diversos problemas, tanto de pele como de cabelo (PERETTO, 2008). 
O cosmético ideal para ser utilizado é aquele que não contém muito produto químico, quanto mais natural, melhor, pois esses aditivos podem se tornar agressivos (PERETTO, 2008).

Ao combinar a argila com outros elementos curativos naturais, o efeito é amplificado. A argila irá absorver as propriedades terapêuticas das ervas e óleos utilizados, repassando esses benefícios para a pele. Por exemplo, o mel pode ser utilizado em todas as receitas, pois tem o efeito de brilho e maciez, além de aumentar o tempo de secagem, prolongando a aplicação da argila (PERRETO, 2008).

\section{Aditivos que melhoram os cosméticos junto com a argila:}

- Abacate: ajuda na queda e crescimento do cabelo, conserva a beleza da pele.

- Camomila: para cabelos claros, deixando sedosos e com mais brilho.

- Mel: para cabelos secos, queimados pelo sol, mar ou piscina; dá brilho e maciez; também indicado para eczemas.

- Óleo de amêndoa: hidrata, suaviza, restaura a oleosidade da pele.

- Pólen de flores: indicado após cirurgias, para reconstituição da pele, e nos casos de exposição excessiva ao sol (PERRETO, 2008).

\section{Argila e seu uso veterinário}

Havendo pouca diferença no tratamento em humanos, o uso da argila nos animais traz como maior dificuldade sua aplicação. Os bichos, quando afetados com alguma doença febril rapidamente buscam um local fresco, onde cavam até encontrar terra úmida e ali se deitam (PERRETO, 2008).

Animais com gangrena, por exemplo, procuram ficar em lugares lamacentos. Eles procuram estes locais por instinto. Se os observarmos, aprenderemos muito com eles (PERRETO, 2008).

\section{Geoterapia}

Geoterapia, lamaterapia ou argilotrapia é o uso da terra no combate das doenças. Este costume é tão antigo quanto à própria humanidade. O que há de novo somente é seu modo de aplicação, cada vez mais aprimorado pela observação e pelas experiências (PERRETO, 2008).

Segundo Medeiros (2013), a palavra geoterapia origina-se da combinação geo $=$ argila e terapia $=$ tratamento. Entre inúmeras práticas que aproveitam os recursos da natureza em prol à saúde do ser humano, este preserva o título de ser milenar. Existem relatos de que o médico grego Discórides utilizava a argila para tratamento e cicatrização, pois a cura era mais rápida. 
Posteriormente, renomados naturalistas contribuíram na difusão desses conhecimentos, o Padre Kneipp e seu discípulo Adolf Just, que é considerado o pai da geoterapia, difundiu resultados de muitos anos dedicados ao estudo da terra. Ele observou que seus pacientes aceleravam a sua recuperação quando deitados na terra nua ou em grama (PERETTO, 2008).

A geoterapia tem princípios na geologia, geoquímica e geofísica em sua utilização, trabalhando além do físico, o emocional e o energético. Mesmo tratando-se de uma técnica muito antiga, ainda se encontram poucas publicações no Brasil (MEDEIROS, 2007).

A "lama" é um agente de desintoxicação e regeneração física, além de eliminar o que é nocivo ao organismo, ela vitaliza os tecidos enfermos, descongestiona e normaliza a circulação do sangue. Além disso, é acessível a todas as classes sociais por ser um remédio barato e de fácil localização (PERETTO, 2008).

Segundo o autor Spethmam (2004), a compressa é o método mais utilizado na geoterapia, podendo ser aplicada pura ou combinada com outros elementos, como, óleo de amêndoa, vinagre, mel, abacate, camomila, pólen de flores.

"Essas compressas de argila podem ser aplicadas em qualquer região do corpo, diretamente no local enfermo" (SPETHMAM, 2004), dentre esses locais, destaca-se a cabeça, tórax, pernas, pés e lombar.

A duração da aplicação das compressas é de no máximo duas horas. A geoterapia é uma prática não recomendada para gestantes ou pacientes no período menstrual (CLAUDINO, 2010).

Várias são as enfermidades que a geoterapia pode tratar. A (tabela 1) descreve as doenças e o tratamento geoterápico indicado para tal enfermidade e a região do corpo na qual deve ser aplicada (CLAUDINO, 2010).

Tabela 1. Doença e tratamento geoterápico indicado:

\begin{tabular}{l|l}
\hline Abcessos & $\begin{array}{l}\text { Compressa de argila verde com mel de abelha. Deixar agir } \\
90 \text { minutos, uma vez por dia. A aplicação deve continuar até } \\
\text { a cicatrização. }\end{array}$ \\
\hline Acnes, espinhas e cravos. & $\begin{array}{l}\text { Compressa de argila rosa com vinagre de maçã, deixar agir } \\
\text { por } 60 \text { minutos em dias alternados até a pele normalizar-se. } \\
\text { Para remoção da máscara utilizar água fria ou chá de } \\
\text { camomila. }\end{array}$ \\
\hline Artrite & $\begin{array}{l}\text { Compressa levemente aquecida de argila branca, aplicação } \\
\text { no local afetado, nos dois pés e nas mãos (cobrir os dedos). } \\
\text { Deixar agir por 90 minutos, de duas a três aplicações por dia, } \\
\text { até quando o problema persistir. }\end{array}$ \\
\hline Assaduras & $\begin{array}{l}\text { Preparar argila verde com chá morno ou frio da planta cipó } \\
\text { azougue. Deixar agir por 45 a 60 minutos e realizar a } \\
\text { remoção com o próprio chá ou água fria. O uso deve ser feito } \\
\text { até quando o problema persistir. }\end{array}$ \\
\hline
\end{tabular}


Usado para desintoxicar e como calmante geral do sistema nervoso, nos processos de ansiedade e depressão. Utiliza-se a pasta de argila branca com gengibre cru espalhando por todo corpo deixando agir por 60 minutos. Em seguida, tome uma ducha morna ou mergulhe em uma banheira, removendo a argila com uma bucha vegetal para uma esfoliação natural.

Bronzeado: como manter Compressa de argila verde com extrato de uva. Aplique uma pasta grossa e cremosa sobre as partes que deseja manter o bronzeado deixando agir por 60 minutos. Aplicação deve ser feita uma vez por semana.

Bursite $\quad$ Compressa de argila verde com chá morno das folhas de
beladona por 90 minutos, de duas a três vezes por dia. Recomenda-se acupuntura com moxabustão (um tipo de acupuntura térmica).

Cabelos: fortalecer e estimular Aplicar a pasta de argila verde com vinagre de maçã por todo o crescimento. o couro cabeludo, de duas a três vezes por semana.

Candidíase
Compressa de argila verde com vinagre de maçã, no baixo do ventre, deixando agir por 60 minutos, uma vez por dia, durante 5 dias. Recomenda-se banho de assento com vinagre de maçã uma a três vezes por dia.

Coluna vertebral: dor Pasta de argila verde aquecida, aplicar uma camada bem grossa por toda a coluna, deixando agir por 90 minutos. Para remoção, usar água de gengibre aquecida. A aplicação deve ser feita até o problema ser resolvido.

\begin{tabular}{l|l}
\hline Dor de cabeça & Compressa de argila verde misturada com suco de batata na
\end{tabular} testa e nas têmporas, deixando agir por 90 minutos durante 30 dias. Quando as crises forem muito acentuadas, fazer uma espécie de "capacete" envolvendo toda a cabeça e a nuca.

Dores musculares Pasta de argila vermelha com chá de canela, erva doce e sementes de mostarda, deixando agir 60 minutos no local desejado. Aplicação deve ser feita até o problema ser resolvido.

Estrias

Pasta de argila branca com mamão papaia maduro. Fazer duas aplicações por dia, durante 90 minutos, removendo com água fria. Após remoção, massagear com óleo de amêndoa ou andiroba. O uso deve ser feito até o problema ser resolvido.

\begin{tabular}{l|l}
\hline Manchas do sol & $\begin{array}{l}\text { Pasta de argila amarela com folhas moídas de estévia, aplica- } \\
\text { se sobre as machas durante } 90 \text { minutos, todos os dias, por } \\
\text { quanto tempo desejar. }\end{array}$ \\
\hline Manchas na pele (em geral) & $\begin{array}{l}\text { Argila branca ou verde, aplicando sobre as manchas por 90 } \\
\text { minutos, diariamente, por quanto tempo desejar. }\end{array}$ \\
\hline $\begin{array}{l}\text { Máscara para limpar e clarear a } \\
\text { pele }\end{array}$ & $\begin{array}{l}\text { Pasta de argila rosa com vinagre de maçã, aplique sobre o } \\
\text { local desejado por } 60 \text { minutos, removendo a argila com água } \\
\text { fria, após o uso recomenda-se o uso de um hidratante natural. } \\
\text { Fazer a aplicação de duas a três vezes por semana durante 3 } \\
\text { meses, e após esse período durante 15 dias para manutenção. }\end{array}$ \\
\hline Máscara rejuvenescedora & $\begin{array}{l}\text { Pasta de argila preta com suco de uva, aplicar em todo local } \\
\text { desejado, deixando por 90 minutos fazendo de duas a três } \\
\text { aplicações durante 3 meses, e após esse período manutenção } \\
\text { a cada 10 dias. }\end{array}$ \\
\hline
\end{tabular}




\begin{tabular}{|c|c|}
\hline Olheiras & $\begin{array}{l}\text { Pasta de argila branca com suco de pepino com casca, fechar } \\
\text { os olhos e aplique sobre eles por cerca de } 30 \text { minutos, de } \\
\text { duas a três vezes por semana, até o problema ser resolvido. } \\
\text { Retirar a compressa com algodão umedecido com água. }\end{array}$ \\
\hline Peles oleosas (hidratar) & $\begin{array}{l}\text { Aplicar argila branca com clara de ovos durante } 60 \text { minutos, } \\
\text { todos os dias até o problema ser resolvido. A clara de ovo é } \\
\text { rica em albumina (responsável, entre outras coisas, por dar } \\
\text { firmeza a pele). }\end{array}$ \\
\hline Peles secas e normais (hidratar) & $\begin{array}{l}\text { Aplicar argila branca com polpa de abacate e mel durante } 60 \\
\text { minutos todos os dias. }\end{array}$ \\
\hline Queimaduras & $\begin{array}{l}\text { Após higienizar bem o local, aplique a clara de ovo batida e } \\
\text { deixe agir. Depois de cicatrizada faça aplicação de argila } \\
\text { roxa deixando agir por } 60 \text { minutos diariamente, por } 30 \text { dias. } \\
\text { Além de o tratamento ajudar na cicatrização, provavelmente } \\
\text { deixará o local sem marcas. }\end{array}$ \\
\hline Rugas & $\begin{array}{l}\text { Aplique argila verde ou branca misturada com extrato de } \\
\text { tomate e mel sobre os locais afetados, deixando agir por } 60 \\
\text { minutos, fazer aplicação diariamente até quando julgar } \\
\text { necessário. }\end{array}$ \\
\hline Sardas & $\begin{array}{l}\text { Aplicar argila verde com suco fresco de planta dente de leão } \\
\text { sobre a área afetada, ou no rosto inteiro. }\end{array}$ \\
\hline Varizes & $\begin{array}{l}\text { Aplique uma camada grossa de argila verde misturada com } \\
\text { vinagre natural de maçã ou suco de gengibre sobre as } \\
\text { varizes, uma ou duas vezes por dia, deixando agir por } 60 \\
\text { minutos, durante } 30 \text { dias. }\end{array}$ \\
\hline Vasinhos sanguíneos & $\begin{array}{l}\text { Preparar a argila verde com vinagre de maçã deixando agir } \\
\text { por } 90 \text { minutos em aplicações diárias. Quando os vasinhos } \\
\text { desaparecerem continue a aplicação durante } 15 \text { dias para } \\
\text { manutenção. Recomenda-se, durante a noite, utilizar vinagre } \\
\text { de maçã natural e com uma bucha vegetal, fazer massagens } \\
\text { no local afetado. }\end{array}$ \\
\hline
\end{tabular}

Fonte: Claudino, 2010.

\section{Cuidados na aplicação da geoterapia}

Assim como toda a prática com várias indicações, segundo a autora Medeiros (2013), a geoterapia não é contraindicada nos casos a seguir, porém exige cuidados nos procedimentos envolvendo a aplicação.

Em caso de ferimentos abertos, não deve haver aplicação diretamente em cima da lesão, em especial lesão profunda. Para auxiliar na cicatrização a recomendação é utilizar a argila ao redor da lesão (MEDEIROS, 2013).

Em caso de diabetes, a geoterapia deve ser aplicada com cuidado, uma vez que existe a possibilidade de lesão da pele. Já em hipertensos, deve-se cuidar a frequência com qual a argila é utilizada, pois pode haver aumento da circulação sanguínea (MEDEIROS, 2013). 
Nos casos de crianças, gestantes e idosos, deve ser mantido o cuidado em relação à pele dos diabéticos, uma vez que são peles delicadas e que necessitam de atenção (MEDEIROS, 2013).

\section{Processo de extração das argilas}

A argila pode ser encontrada em casas de produtos naturais e olarias, é importante que seja limpa, que não tenha pedras, impurezas ou cacos de vidro. A terra ideal deve ser totalmente natural, virgem e sem químicos (PERRETO, 2008).

O produto deve ser retirado do subsolo, abaixo do húmus. Outra fonte em que pode ser encontrada, são as casas de olarias, porém nestas a dificuldade para encontrar a argila no seu estado ideal é mais acentuada (PERETTO, 2008).

Segundo a Constituição Federal de 1988, a argila é um recurso mineral do subsolo que necessita de autorização do Departamento Nacional de Produção Mineiral (DNPM), pois é um bem da união.

\section{Cuidados com a argila}

Como em muitos casos precisamos da argila com rapidez, em caso de acidentes, por exemplo, ela pode ser conservada em um recipiente higienizado e bem tampado, por tempo indefinido. É de extrema importância que fique exposta ao sol pouco tempo antes do uso, para absorver o magnetismo solar. A argila utilizada após o tratamento, tendo absorvido impurezas, fica saturada e deve ser descartada (PERETTO, 2008).

\section{Temperaturas}

Geralmente a temperatura a ser utilizada é determinada pelo tratamento e local da doença. Uma pele quente, congestionada, pede cataplasmas frias, já uma pele fria, requer cataplasmas quentes (PERETTO, 2008).

O cataplasma quente é relaxante, ativa circulação, eliminando toxinas e aliviando os tecidos. Já se o local estiver quente e febril, a argila deve ser utilizada fria, um cataplasma frio refresca, descongestiona e desinflama, melhorando a circulação (MEDEIROS, 2013).

Para o aquecimento da argila, deve-se utilizar o banho-maria, até chegar a temperatura almejada. A argila também pode ser aquecida no sol (PERRETO, 2008).

A temperatura fria a que referimos é de temperatura ambiente, já a temperatura morna é mais utilizada em pacientes sensíveis, como idosos e crianças, ou até mesmo em pessoas com aversão ao frio (MEDEIROS, 2007). 


\section{Metodologia}

Trata-se de uma revisão bibliográfica onde foram utilizados dados obtidos a partir da literatura disponível.

Para a coleta de dados foram utilizados livros, artigos e dissertações com o tema Argiloterapia. Os artigos foram pesquisados nos bancos de dados do Google acadêmico, SciELO, compreendidos no período de 1990 até 2016. Palavras de busca: Argila, Argiloterapia, Geoterapia, Tratamentos estéticos com argila, Terapias com argila.

O material científico foi lido e seus dados analisados e discutidos. Uma tabela foi elaborada com as informações de cores das argilas e tratamentos geoterápicos utilizados.

\section{Resultados e Discussão}

Em todos os autores pesquisados, foi observado que a argila tem grande importância e potencial para os usos terapêuticos e tratamentos estéticos. Há vários tipos de argila, cada uma com características próprias e diferentes indicações, sendo que as mais representativas são as argilas verde e branca.

Atualmente, a argila é utilizada em vários produtos na indústria cosmética, por ser um mineral abundante no Brasil, economicamente viável e ao ser descartado não agredir o meio ambiente. Suas propriedades tecnológicas são a desintoxicação e tonificação.

Em 2012, foram publicados dois artigos que comprovam o potencial cosmético da argila. O primeiro, realizado no Brasil, demostrou que, em sete dias de uso da argila, era possível observar considerável estímulo de fibras de colágeno, o que é benéfico para o tratamento antienvelhecimento. O segundo, feito na Alemanha, comprovou a eficácia da argila em tratamentos de acne e lesões formadas na pele, combinada com óleo de jojoba.

Dentre suas aplicações, o seu destaque é na cosmetologia, pois está relacionado às afecções que acometem a pele como: acne, envelhecimento cutâneo, discromias, entre outras. Essas anomalias causam desconforto nas pessoas, principalmente em locais visíveis como a face, ocasionando baixa autoestima. Segundo alguns estudos, para cada tipo de tratamento é utilizado um tipo de argila. Utiliza-se a verde para revitalizar, amarela rejuvenescer, preta regeneração celular e a rosa para efeito hidratante.

Cada argila contém características relacionadas aos usos terapêuticos, as cores são aspectos contribuintes para esta diferenciação. A utilização correta irá depender da avaliação de um bom profissional, que indicará a cor adequada a ser utilizada, bem como a necessidade do seu uso e o local. 
Através desse estudo, baseado em diferentes autores, pode-se chegar a uma conclusão para essa revisão bibliográfica. A tabela 2 abaixo mostra os resultados obtidos no estudo da geoterapia.

Tabela 2. Revisão da literatura sobre o uso da Argila

\begin{tabular}{|c|c|c|c|c|}
\hline AUTOR & $\begin{array}{c}\text { TÍTULO DO } \\
\text { TRABALHO }\end{array}$ & ANO & RESULTADOS & ARGILA \\
\hline HENKE, S.L. & $\begin{array}{l}\text { Estrutura } \\
\text { Cristalina }\end{array}$ & 2012 & $\begin{array}{l}\text { Estimula músculos e } \\
\text { articulações que estão } \\
\text { enrijecidas. }\end{array}$ & \multirow[t]{4}{*}{ VERMELHA } \\
\hline $\begin{array}{lr}\text { GOPINATH, } & \text { T.R.; } \\
\text { CRUZ, } & \text { A.V.C.; } \\
\text { FREIRE, J.A. } & \end{array}$ & $\begin{array}{l}\text { Estudo } \\
\text { comparativo da } \\
\text { composição } \\
\text { química e as } \\
\text { variedades de } \\
\text { argilas } \\
\text { bentoníticas. }\end{array}$ & 2003 & $\begin{array}{l}\text { Ajuda na circulação do } \\
\text { sangue. }\end{array}$ & \\
\hline $\begin{array}{l}\text { SAMPAIO, } \\
\text { ANDRADE, } \quad \text { M.C.; } \\
\text { DUTRA, } \\
\text { PENNA, M.T.M. }\end{array}$ & $\begin{array}{l}\text { Manganês: } \\
\text { comunicação } \\
\text { técnica elaborada } \\
\text { para o livro } \\
\text { rochas minerais } \\
\text { industriais: usos e } \\
\text { especificações. }\end{array}$ & 2008 & $\begin{array}{l}\text { Melhora no } \\
\text { descongestionamento das } \\
\text { mucosas. }\end{array}$ & \\
\hline STARIOLO, D. & $\begin{array}{l}\text { Introdução a a } \\
\text { Física da Matéria } \\
\text { Condensada. }\end{array}$ & 2009 & $\begin{array}{l}\text { Contraindicado para } \\
\text { pessoas com febre, } \\
\text { hipertensão, inflamação } \\
\text { ou muito estresse. Esta } \\
\text { cor aumenta a circulação } \\
\text { sanguínea. }\end{array}$ & \\
\hline $\begin{array}{l}\text { PERIODICO DE } \\
\text { DOCUMENTAÇÃO } \\
\text { PROFISSICONAL EM } \\
\text { ESTÉTICA }\end{array}$ & Vida Estética & 2004 & $\begin{array}{lr}\text { Combate } & \text { o } \\
\text { envelhecimento precoce. } & \text { efeito } \\
\text { Tem } & \text { e } \\
\text { remineralizante } & \text { Nutre, } \\
\text { iluminador. } & \text { hidrata. } \\
\text { tonifica e } \\
\text { Eliminação de resíduos. } \\
\text { Tonifica a pele depois de } \\
\text { exposição solar. Elimina } \\
\text { manchas causadas pela } \\
\text { radiação solar. }\end{array}$ & AMARELA \\
\hline PERETTO, I.C. & $\begin{array}{l}\text { Argila: um santo } \\
\text { remédio e outros } \\
\text { remédios } \\
\text { compatíveis }\end{array}$ & 1999 & $\begin{array}{l}\text { Auxilia na circulação } \\
\text { sanguínea, promovendo a } \\
\text { remoção de toxinas. }\end{array}$ & VERDE \\
\hline MEDEIROS, G.M. DA & Geoterapia: & 2007 & Descongestionante & \\
\hline
\end{tabular}


FAZ CIÊNCIA, VOL. 22, N. 36, JUL/DEZ DE 2020 - P. 143-163

\begin{tabular}{|c|c|c|c|c|}
\hline S. & $\begin{array}{l}\text { teorias } \\
\text { mecanismos de } \\
\text { ação um manual } \\
\text { teórico-prático }\end{array}$ & & $\begin{array}{l}\text { bastante usado em } \\
\text { massagens para que o } \\
\text { sistema linfático esteja } \\
\text { em equilíbrio. }\end{array}$ & \multirow{5}{*}{ VERDE } \\
\hline CLAUDINO, H. & $\begin{array}{l}\text { Argila medicinal: } \\
\text { propriedades } \\
\text { benefícios e uso } \\
\text { na saúde estética. }\end{array}$ & 2010 & $\begin{array}{l}\text { Muito utilizada como } \\
\text { esfoliante. }\end{array}$ & \\
\hline EVELINE, C. & $\begin{array}{ll}\text { Máscaras: } & \text { as } \\
\text { estrelas } & \text { da } \\
\text { cosmetologia. } & \end{array}$ & 2010 & $\begin{array}{l}\text { Utilizada em vários } \\
\text { tratamentos } \\
\text { principalmente nos casos } \\
\text { crônicos. }\end{array}$ & \\
\hline $\begin{array}{l}\text { VILA Y } \\
\text { COMPANYA, M. }\end{array}$ & $\begin{array}{l}\text { Manual de } \\
\text { geoterapia } \\
\text { aplicada }\end{array}$ & 2000 & Ação emoliente & \\
\hline HAUK, L.B.P. & $\begin{array}{l}\text { Curso } \\
\text { geoterapia } \\
\text { estética } \\
\text { Atualização em } \\
\text { geoterapia: } \\
\text { aperfeiçoamento } \\
\text { dos } \\
\text { conhecimentos } \\
\text { em geoterapia } \\
\text { direcionados a } \\
\text { prática clínica em } \\
\text { estética facial } \\
\text { utilizando a a } \\
\text { matéria argila } \\
\text { como } \\
\text { potencializador } \\
\text { da beleza e } \\
\text { saúde. }\end{array}$ & 2011 & $\begin{array}{l}\text { Recomenda-se o uso para } \\
\text { peles com acnes, pois sua } \\
\text { composição regula a } \\
\text { oleosidade da pele. }\end{array}$ & \\
\hline HAUK, L.B.P. & $\begin{array}{lr}\text { Curso } & \text { de } \\
\text { geoterapia } & \text { e } \\
\text { estética } & \text { e } \\
\text { Atualização em } & \end{array}$ & 2011 & $\begin{array}{l}\text { Promove efeitos eficazes } \\
\text { na suavização das linhas } \\
\text { de expressão e manchas, } \\
\text { principalmente naquelas } \\
\text { causadas pela exposição } \\
\text { solar. }\end{array}$ & BRANCA \\
\hline BONDS, L.V. & $\begin{array}{l}\text { A cura pelas } \\
\text { cores }\end{array}$ & 1999 & $\begin{array}{l}\text { Serve como porta de } \\
\text { entrada para outros } \\
\text { tratamentos }\end{array}$ & ROSA \\
\hline MEDEIROS, G.M.S. & $\begin{array}{l}\text { O poder da argila } \\
\text { medicinal: } \\
\text { princípios } \\
\text { teóricos } \\
\text { procedimentos } \\
\text { terapêuticas e } \\
\text { relatos } \\
\text { experiência } \\
\text { clínicas. }\end{array}$ & 2013 & $\begin{array}{l}\text { Propriedade de tonificar a } \\
\text { pele; realçar brilho e } \\
\text { maciez, promovendo } \\
\text { elasticidade. } \\
\text { Antioxidante, relaxante. }\end{array}$ & \\
\hline
\end{tabular}


FAZ CIÊNCIA, VOL. 22, N. 36, JUL/DEZ DE 2020 - P. 143-163

\begin{tabular}{|c|c|c|c|c|}
\hline BONDS, L.V. & $\begin{array}{l}\text { A cura pelas } \\
\text { cores }\end{array}$ & 1999 & $\begin{array}{lr}\text { Ativa } & \text { circulação } \\
\text { sanguínea; possui efeito } \\
\text { adstringente; } \\
\text { inflamatório; cicatrizante } \\
\text { e antisséptico. }\end{array}$ & PRETA \\
\hline MEDEIROS, G.M.S. & $\begin{array}{l}\text { O poder da argila } \\
\text { medicinal: } \\
\text { princípios } \\
\text { teóricos } \\
\text { procedimentos } \\
\text { terapêuticas } \quad \mathrm{e} \\
\text { relatos } \\
\text { experiência } \\
\text { clínicas. }\end{array}$ & 2013 & $\begin{array}{l}\text { Nutre a pele, suaviza e } \\
\text { revitaliza. }\end{array}$ & ROXA \\
\hline CLAUDINO, H. & $\begin{array}{l}\text { Argila medicinal: } \\
\text { propriedades } \\
\text { benefícios e uso } \\
\text { na estética. }\end{array}$ & 2010 & $\begin{array}{l}\text { Sendo a mais indicada } \\
\text { para terapia capilar; } \\
\text { Reconstrução da pele no } \\
\text { caso de lesão. }\end{array}$ & CINZA \\
\hline
\end{tabular}

FONTE: Autor (2020).

\section{Conclusão}

Conclui-se neste trabalho que cada tipo de argila possui propriedades medicinais, com aplicações terapêuticas e estéticas específicas em nosso corpo, de acordo com sua cor e composição físico-química. Apresentam resultados satisfatórios quando utilizadas como complemento em tratamentos estéticos e medicinais.

Sua utilização como um produto natural remonta nossos antepassados. É um produto barato, de fácil aplicação, que não oferece riscos à saúde do paciente como os produtos industrializados, ou seja, não há riscos de uma reação alérgica, por exemplo.

\section{Referências}

BONDS, Lilian V. A CURA PELA COR. Lisboa: Ed. Estampa, 1999.

BOURGEOIS, Pierre. EL EXTRAORDinÁrio PODER CURATIVO DE LA ARGILA. Barcelona: De Vicchi, 2006.

BRASIL. ANVISA. RESOLUÇÃO RDC N 67, DE 8 DE OUTUBRO DE 2007. Anexo I Que Institui As Boas Práticas De Manipulação Em Farmácias. Disponível em: http://elegis.anvisa.gov.br/leisref/public/showAct. php?id=28806\&word=. Acesso em: 05/05/2016.

CLAUDINO, Hilton. ARGILA MEDICINAL. São Paulo: Ed. Elevação, 2010.

CORVO, Joseph; BONDS, Lilian V. O PODER DE CURA DA CROMOZONOTERAPIA: E COMO ELA PODE AJUDAR VOCÊ. São Paulo: Copyright, 1997.

DEBACHER, Nito A.; MELLO, C. A. Dian de. EFEITO NAS PROPRIEDADES REOLÓGICAS DA ARGILA COM ADIÇÃO DE UM POLÍMERO. Florianópolis: Sociedade Brasileira de Química, 2004.

DÍAZ, Lourdes M. ARCILLAS Y PELOIDES EN MEDICINA ESTÉTICA. Madri, 2004. 
DORNELlAS, Eliane; MARTINS, Sheila. O PODER DAS ARGILAS: GEOTERAPIA. São Paulo, 2009. Disponível em: https://pt.scribd.com/document/260300786/O-Poder-Das-Argilas. Acesso em: 20 maio 2016.

FONTES, Mauricio P. F.; CAMARGO, Otávio A. de; SPOSITO, Garrison. ELETROQUÍMICA DAS PARTÍCULAS COLOIDAIS E SUA RELAÇÃO COM A MINERALOGIA DE SOLOS ALTAMENTE INTEMPERIZADOS. Viçosa: UFV, 2001.

EVELINE, Claudia. MÁSCARAS: AS ESTRELAS DA COSMETOLOGIA. São Paulo: Bel. Col., 2010.

GOPINATH, Thiago R.; CRUZ, Almeida V.C.; FREIRE, João, A. ESTUDO COMPARATIVO DA COMPOSIÇÃO QUIMICA E AS VARIEDADES DE ARGILAS DA REGIÃO DA BOA VISTA, Paraíba. Paraíba, Revista de Geologia, vol 16, n. 1, pag. 35-48, 2003.

HAUCK, Lívia. B. P. CURSO DE GEOTERAPIA ESTÉTICA E ATUALIZAÇÃO EM GEOTERAPIA: APERFEIÇOAMENTO DOS CONHECIMENTOS EM GEOTERAPIA DIRECIONADOS A PRÁTICA CLÍNICA EM ESTÉTICA FACIAL UTILIZANDO A METÉRIA ARGILA COMO POTENCIALIZADOR DA BELEZA E DA SAÚDE. Florianópolis- SC. Lótus, 2011.

HENKE, Sérgio L. ESTRUTURA CRISTALINA. Nota de aula. UFPR. Curitiba, 2012. Disponível

em:ftp://ftp.demec.ufpr.br/disciplinas/EngMec_NOTURNO/tm336/notas/aula\%203\%20Estrutur a\%20cristalina\%20 [Modo\%20de\%20Compatibilidade] \%20-\%20C\%F3pia.pdf. Acesso em: 28 agosto de 2016.

LAMAITA, Giovana. ARGILOTERAPIA: MENOS TOXINA E MAIS VITALIDADE. Disponível em: <http://absoluta-beleza.blogspot.com.br/2008/09/argilaterapia-os-mistriose.html>. Acesso em: 01 de agosto de 2016.

LANGREO, Núria. Salud y Belleza con Arcillas, fangos y algas. Barcelona: Tikal, 1999. 269p.

MEDEIROS, Graciela M. da S. de. GEOTERAPIA: TEORIA E MECANISMO DE AÇÃO: UM MANUAL PRÁTICO TEORICO. Tubarão: Ed. UNISUL, 2007.

MEDEIROS, Graciela M. da S. de. O PODER DA ARGILA MEDICINAL. Blumenau: Ed. Nova Letra, 2013.

PERETTO, Iracela C. ARGILA: UM SANTO REMÉDIO E OUTROS REMÉDIOS COMPATÍVEIS. São Paulo: Paulinas, 2008.

PERIÓDICO DE DOCUMENTAÇÃO PROFISSIONAL EM ESTÉTICA, VIDA E ESTÉTICA. Rio de Janeiro-RJ: Editores: Luiz Fernando Lomba e Luiz Marcos Lomba, 2004.

RIBEIRO, Claúdio de J.. COSMETOlOGiA APLICADA A DERMOESTÉTICA. 2ed. São Paulo: Phammabooks, 2010.

SANTOS, Ines. ARGILAS: DIVERSAS FORMAS DE USAR. São Paulo, 2015. Disponível em: http://diariodeinessantos.blogspot.com.br/2015/07/argila-verde.html. Acesso em: 01 de outubro de 2016.

SAMPAIO, João A.; ANDRADE, Mônica C. de; DUTRA, Achilles B. J; PENNA, Márcio T. M.. MANGANÊS: COMUNICAÇÃO TÉCNICA ELABORADA: USO E ESPECIFICAÇÕES. Parte 2. Centro de Tecnologia Mineral. Rio de Janeiro, pág. 633-648. Cap.28, 2008. 
SILVA, Marinilda N. P. da; SILVA, Marly N. P. da; BARRIONUEVO, Bruno de U. S.; FEITOSA, Igor M.; SILVA, Givanildo S. da. REVESTIMENTOS CERÂMICOS E SUAS APLICABILIDADES. Macéio, Vol 2. Ed. Ciências exatas e tecnológicas, 2015

SOUZA, Valeria M. ATIVOS DERMÁtologicos, Vol2.1. ED. SÃo PAULO: Phambooks, 2005

SPETHMANN, Carlos N. MEDICINA ALTERNATIVA DE A A Z. 7. ed. Uberlândia - Mg: Natureza, 2004.

STARIOLO, Daniel. INTRODUÇÃO A FISICA DA MATÉRIA CONDENSADA. Departamento de Física Universidade Federal do Rio Grande do Sul. Porto Alegre, 2009. Disponível em: http://www.if.ufrgs.br/ starioloensino/curso_2009.pdf. Acesso em: 08 de agosto de 2016.

VILA Y CAMPANYA, María. MANUAL DE GEOTERAPIA APLICADA. ORGANIZACIÓN PANAMERICANA DE LA SALUD. ORGANIZACIÓN MUNDIAL DE LA SALUD. Programa Nacional de Medicina Complementária. Peru. Textos completos, 2000. Disponível em: Acesso em: 06 setembro 2016.

Recebido em 04/05/2020 - Aprovado em 20/07/2020. 